\title{
Stresses Analysis on Spur Gear for Different Contact Ratio
}

\author{
Khin Khin Thant ${ }^{1}$, Chaw Wint Yee Zaw ${ }^{2}$ and Khin Thu Zar \\ ${ }^{1-3}$ Department of Mechanical Engineering \\ Technological University (Thanlyin)
}

Myanmar

\begin{abstract}
This paper concentrated on the effect of contact ratio on the contact stresses generated on meshing spur gear teeth during the power transmission. In this study, various contact ratios of spur gear teeth have been analyzed. For this contact ratio considered, the rate of loads sharing and angular position of loads were determined on the involute profile of meshing tooth of each gearing. In addition to that, the different stress conditions of this tooth for the critical position (at the instant when the generated contact stress is at the maximum state) are determined. From this study, it is clear that the highest contact ratio resulted in the lowest generated tooth stress (i.e. the highest load-carrying capacity). This approach reduced the contact stresses for power transmission. At last, the results obtained from Hertz's contact stress formula and AGMA contact stress formula, and then compared allowable stress. They are comparable to each other.
\end{abstract}

Key Words: Spur Gear, Contact ratio, Tooth profile, Load Sharing, Stresses.

\section{INTRODUCTION}

Gears are the most common types of transmitting power in the modern mechanical engineering world. They change the rate of rotation of machinery shaft and also the axis of rotation. For high speed machinery, such as an automobile transmission, gears are the optimal medium for low energy loss and high accuracy. Their function is to convert input provided by prime mover into an output with lower speed and corresponding higher torque. Toothed gears are used to transmit the power with high velocity ratio. During this phase, they encounter high stress at the point of contact. A pair of teeth in action is generally subjected to two types of cyclic stresses:

1. Bending stresses inducing bending fatigue

2. Contact stresses causing contact fatigue [1].

Both these types of stresses may not attain their maximum value at the same point of contact. However, combined action of both of them is the reason of failure of gear tooth leading to fracture at the root of a tooth under bending fatigue and surface failure, due to contact fatigue. When loads are applied to the bodies, their surfaces deform elastically near the point of contact.

S.C.Mohanty suggested an analytical method to calculated the individual tooth load during meshing cycle, also he referred to determination of the locations and sizes of contact zones along the path of contact for high contact ratio gearing $(3<\mathrm{CR}<2)$ [2]. A.H.Elkholy introduced a method to determine tooth load sharing especially for high contact ratio spur gear. [3].In this paper, the study of the various contact ratio and generated tooth contact stresses. In this case of the contact ratio 1.6, 1.7, 1.8, 1.9 and 2.0 had been studied, as these ratios are used in gear sets in heavy machinery. In each case, the tooth contact stresses was calculated.

\section{TYPE OF GEARS}

There are many types of gears used in engineering as set out in Australian Standard AS-2075 Glossary of Terms and Notations for Gears. Spur gears are the most common types of gears.

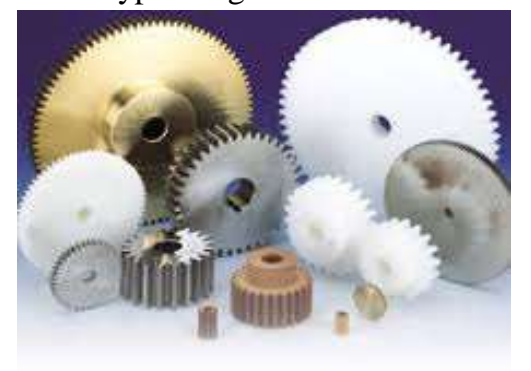

Figure1. Spur Gear 
They are characterized by teeth, which are perpendicular to the face of the gear. Spur gears are by far the most commonly available, and are generally the least expensive. They are used to transmit rotary motion between parallel shaft i.e., they are usually cylindrical in shape shown in Fig.1, and the teeth are straight and parallel to the axis of rotation [4].

\section{CONTACT RATIO}

Contact ratio can defined as a number of teeth in contact at one time as these teeth pass through the contact zone. It is impractical to make contact ratio (CR) less than unity. If the contact ratio is one, then one pair of teeth leaves contact just as the next pair begins contact. This is undesirable, because slight error in the tooth spacing will cause oscillations in the velocity, vibration and noise. Gears should not generally be designed having contact ratios less than about 1.2, because inaccuracies in the mounting might reduce the contact ratio even more, increasing the possibility of impact between the teeth as well as an increase in the noise level. Thus, even though a contact ratio 1.2 is acceptable, a minimum contact ratio of 1.4 is preferred and larger is better [5]. A contact ratio of 2.0 means that there are always two pairs in contact, i.e. at the instant when one pair goes out of contact, a new pair comes in contact. When double pairs of teeth are engaged, the transmitted load will be divided between two meshing teeth.

$\mathrm{CR}=\frac{\mathrm{ARC}}{\mathrm{P}_{\mathrm{c}}}=\frac{\mathrm{PTH}}{\mathrm{P}_{\mathrm{b}} \cos \varphi}=\frac{\mathrm{PTH}}{\mathrm{P}_{\mathrm{b}}}$

where, $\mathrm{CR}=$ contact ratio;

$\mathrm{ARC}=\operatorname{arc}$ of contact;

$\mathrm{PTH}=$ path of contact;

$\varphi=$ pressure angle;

$\mathrm{P}_{\mathrm{b}}=$ circular pitch;

$\mathrm{P}_{\mathrm{c}}=$ baser pitch

\section{TEETH PAIR LOAD SHARING}

The pinion tooth diagram shown in Fig.2 is marked into seven different alphabetical points on the right side to show how the teeth pairs come into contact when they pass the mesh zone.

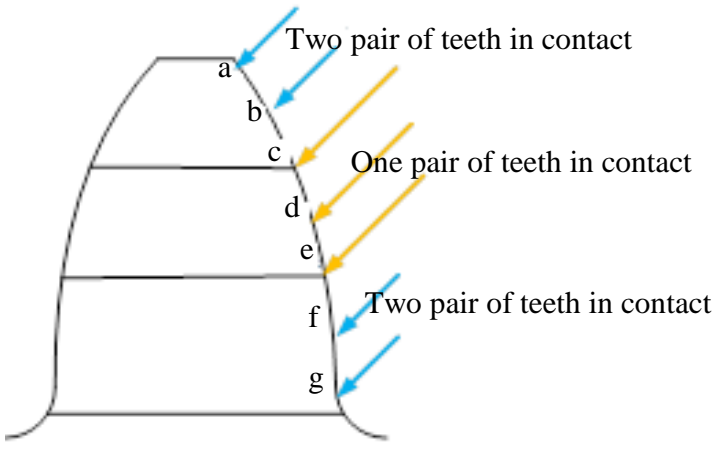

Figure2. Pinion teeth

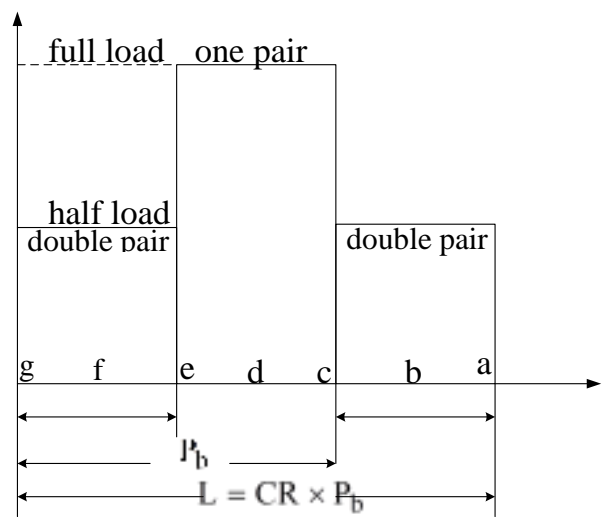

Figure3. Loading along the path of contact

In Fig. 2 and Fig 3, the points are located along the line of action within the interval of the length of action. Considering contact ratio 1.4 and above, the initial contact point for pinion tooth with the gear tooth is point ' $\mathrm{g}$ ', and simultaneously for the second tooth of the same pinion, which is already in mesh will be at point 'c'. Therefore, the load will be shared between these two points similarly points ' $f$ ' and ' $b$ ', also 'e' and ' $a$ ' will have simultaneous action. Then point ' $a$ ' will goes out of contact, 
therefore the full load will be applied starting from point 'e', through point ' $d$ ' until the contact begin at point 'c', then new meshing tooth comes into contact [6]. In normal contact ratio gearing, and when a single pair of tooth is engaged, this pair transmits the full load or full load is then applied on the one mesh tooth only. Almost, critical conditions (for maximum generated contact stresses) occur in the one pair contact zone. When double pairs of teeth are engaging, the transmitted load will divide between two meshing teeth. Load sharing depends on contact ratio and stiffness of meshing tooth at point of application of load. For this reason the load sharing at the point 'd', which is critical position for this case.

\section{GEAR}

The solid model created two spur gears in meshed by using the SOLIDWORKS software, using the parameters shown in Table 1.

Table1. Spur Gear Parameter

\begin{tabular}{|c|c|c|}
\hline Parameter & Pinion & Gear \\
\hline Profile & involute & involute \\
\hline Material & AISI-5160 & AISI-5160 \\
\hline Yield stress & $1790 \mathrm{MPa}$ & $1790 \mathrm{MPa}$ \\
\hline Modulus of & $206.9 \mathrm{GPa}$ & $206.9 \mathrm{GPa}$ \\
\hline Poisson's ratio & 0.3 & 0.3 \\
\hline Number of teeth & 21 & 51 \\
\hline Module & $4 \mathrm{~mm}$ & $4 \mathrm{~mm}$ \\
\hline Face width & $15 \mathrm{~mm}$ & $15 \mathrm{~mm}$ \\
\hline Pressure angle & $20 \mathrm{degree}$ & $20 \mathrm{degree}$ \\
\hline Root fillet & $1 \mathrm{~mm}$ & $1 \mathrm{~mm}$ \\
\hline Maximum torque & $540 \mathrm{Nm}$ & \\
\hline Rotational speed & $350 \mathrm{rpm}$ & \\
\hline Center distance & \multicolumn{2}{|c|}{ OQT 400} \\
\hline Condition & \multicolumn{2}{|c|}{684} \\
\hline Brinell Hardness &
\end{tabular}

\subsection{Force on Gear Teeth}

The power is transmitted from the input shaft to the output shaft. The teeth of pinion drive the teeth of gear and thus transmit the power to the gear. Gears are used to transmit mechanical power and this required applying mechanical torque that can be calculated.For SI unit;

Power, $P=\frac{2 \pi N T}{60}$

where, $\mathrm{P}$ is power transmitted by gears, Watt

$\mathrm{N}$ is speed of rotation,rpm

$\mathrm{T}$ is torque transmitted by gear, $\mathrm{Nm}$

\subsection{Transmitted Force}

The reaction force $\mathrm{F}$ between the mating teeth occur along the pressure line, and the power is transmitted by means of the force exerted by the tooth of the driving gear to the mesh of the driven gear [7]. The reaction force $\mathrm{F}$ can be resolved into two components: a tangential force $F_{t}$ and radial force $F_{r}$ shown in Fig. 4.

Tangential force $\mathrm{F}_{\mathrm{t}}$ is a useful component (load ) because it determines the magnitude of torque and consequently power, which is transmitted. Radial force $F_{r}$ is a separting force, is always toward the center of gear. Transmission gears are required hard wear resistance surface, resistance to tooth root bending fatigue, resistance to surface fatigue which lead to pitting and dimensional accuracy for smooth meshing. 


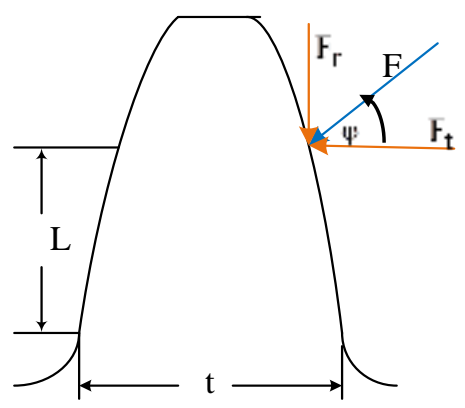

Figure4. Load Transmitted on Spur Gear

Tangential load $F_{t}=\frac{T}{r_{p}}$

Thus the tangential component $F_{t}$ of the transmit load will be

Tangential load $\mathrm{F}_{\mathrm{t}}=\mathrm{F} \cos \varphi$

Radial load $\quad F_{r}=F \sin \varphi$

where, $r_{p}$ is pitch circle radius of pinion $(m)$

$\varphi$ is the pressure angle (degree)

\subsection{Material}

In this paper, the material of AISI-5160 alloy steel is used. AISI-5160 steel is alloy which containing magnesium, titanium and chromium. This material is used in vehical technology. This alloy steel can improved strength, toughness and corrosion resistance of gear.

\section{HERTZ'S CONTACT STRESS}

In many engineering applications, such as rolling bearing, gears, cams, etc., machine component whose function depends upon the rolling and sliding motion in contact along the surfaces while under load [8]. The contact between two surfaces gives rise to an area of contact and a pressure distrubtion over this contact area.If the surfaces have simple geometry, the contact theory of Hertz (1881) can be used for calculation of the contact area and the pressure distribution. The shape of the contact area depends on the shape (curvature) of the contact bodies [9]. When the surfaces of two solid bodies are brought into contact under load, they deform elastically. To illustrate the contact between two elastic bodies, the simpler contact of two parallel cylinders in Fig .6 is presented based on Hertz's theory. 


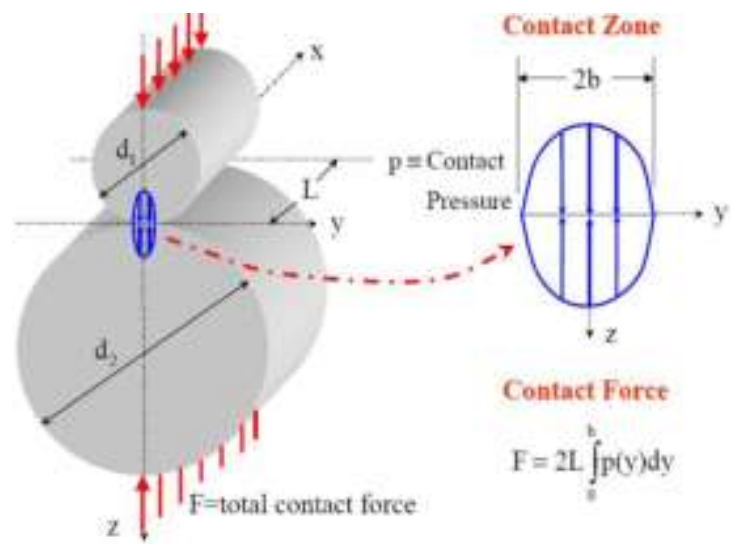

Figure6. Elliptical pressure distribution

The maximum pressure between the cylinder will be

$\mathrm{P}_{\max }=\frac{2 \mathrm{~F}}{\pi \mathrm{bL}}$

$b=\sqrt{\frac{2 F\left(\frac{\left(1-v_{1}^{2}\right)}{E_{1}}+\frac{\left(1-v_{2}^{2}\right)}{E_{2}}\right)}{\pi L\left(\frac{1}{d_{1}}+\frac{1}{d_{2}}\right)}}$

$\mathrm{d}_{1}=\mathrm{d}_{\mathrm{p}} \sin \varphi$

$\mathrm{d}_{2}=\mathrm{d}_{\mathrm{g}} \sin \varphi$

where, $\mathrm{P}_{\max }=$ maximum pressure distribution $(\mathrm{MPa})$;

$\mathrm{b}=$ half of contact width $(\mathrm{m})$;

$\mathrm{L}=$ face width of gear $(\mathrm{m})$;

$v_{1}, v_{2}=$ poisson's ratio of two cylinders;

$\mathrm{E}_{1}, \mathrm{E}_{2}=$ modulus of elasticity of two cylinders $(\mathrm{GPa})$

$\mathrm{d}_{1}, \mathrm{~d}_{2}=$ diameter of two cylinders $(\mathrm{m})$;

$d_{p}, d_{g}=$ diameter of pinion and gear $(m)$;

Table2. Maximum pressure Distribution for various Contact Ratios

\begin{tabular}{|c|c|c|c|c|}
\hline $\begin{array}{c}\text { Contact } \\
\text { ratio } \\
(\mathrm{CR})\end{array}$ & $\begin{array}{c}\text { Critical } \\
\text { radius } \\
(\mathrm{mm})\end{array}$ & $\begin{array}{c}\text { Half of } \\
\text { contact } \\
\text { width } \\
\text { "b"(mm) }\end{array}$ & $\begin{array}{c}\text { Transmitted } \\
\text { tangential } \\
\text { load (N) }\end{array}$ & $\begin{array}{c}\text { Maximum } \\
\text { pressure } \\
\text { distribution } \\
(\mathrm{MPa})\end{array}$ \\
\hline 1.6 & 41.89 & 0.3228 & 12890.8 & 1803.4 \\
\hline 1.7 & 42.29 & 0.3213 & 12767.7 & 1794.8 \\
\hline 1.8 & 42.70 & 0.3197 & 12646.9 & 1786.3 \\
\hline 1.9 & 43.10 & 0.3183 & 12528.4 & 1777.9 \\
\hline 2.0 & 44.56 & 0.2567 & 8150.4 & 1434.0 \\
\hline
\end{tabular}




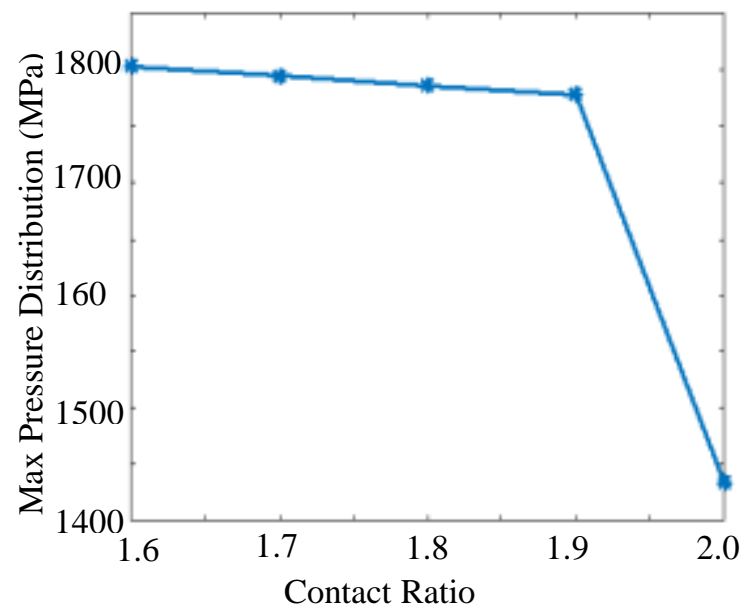

Figure7. Maximum Pressure Distribution \& Contact Ratio

Using these equation the principal stresses and maximum shear stress at $\mathrm{y}=0$ can be calculate as following

$\sigma_{1}=-\mathrm{P}_{\max }\left[\frac{1+2\left(\frac{\mathrm{z}}{\mathrm{b}}\right)^{2}}{\sqrt{1+\left(\frac{\mathrm{z}}{\mathrm{b}}\right)^{2}}}-2\left(\frac{\mathrm{z}}{\mathrm{b}}\right)\right]$

$\sigma_{2}=-2 P_{\max }\left[\sqrt{1+\left(\frac{\mathrm{z}}{\mathrm{b}}\right)^{2}}-\frac{\mathrm{z}}{\mathrm{b}}\right]$

$\sigma_{3}=-\frac{P_{\max }}{\sqrt{1+\left(\frac{\mathrm{z}}{\mathrm{b}}\right)^{2}}}$

These equations are useful for rolling contact occurred between gear teeth. The largest principal stress is compressive and located at the center of the rectangular flat and $-\mathrm{P}_{\max }$ in magnitude. The largest shear stress is approximately $0.3 \mathrm{P}_{\max }$ and is located at about $0.786 \mathrm{~b}$ below the surface [10].

Maximum shear stress, $\tau_{\max }=\frac{\sigma_{1}-\sigma_{2}}{2}$

Maximum von Mises, $\sigma_{\mathrm{von}}=\sqrt{\left(\sigma_{1}-\sigma_{2}\right)^{2}+\left(\sigma_{2}-\sigma_{3}\right)^{2}+\left(\sigma_{3}-\sigma_{1}\right)^{2}}$

Table3. Results of Principal Stresses, Max: Shear Stresses and Max: von Mises Stresses

\begin{tabular}{|c|c|c|c|c|c|}
\hline \multirow{2}{*}{$\begin{array}{c}\text { Contact } \\
\text { Ratio } \\
\text { (CR) }\end{array}$} & \multicolumn{3}{|c|}{ Principal Stresses } & \multirow{2}{*}{$\begin{array}{c}\text { Max: } \\
\text { Shear } \\
\text { Stresses }\end{array}$} & \multirow{2}{*}{$\begin{array}{c}\text { Max: von } \\
\text { Mises } \\
\text { Stresses }\end{array}$} \\
\hline & $\sigma_{1}$ & $\sigma_{2}$ & $\sigma_{3}$ & & \\
\hline 1.6 & -334.7 & -525.7 & -1417.8 & 541.0 & 1009.9 \\
\hline 1.7 & -333.1 & -523.2 & -1411.1 & 538.4 & 1005.1 \\
\hline 1.8 & -331.5 & -520.7 & -1404.4 & 535.9 & 1000.3 \\
\hline 1.9 & -329.9 & -518.2 & -1397.8 & 533.4 & 995.6 \\
\hline
\end{tabular}

\section{CONCLUSION}

The results of maximum contact stress $P_{\max }$, principal stresses $\left(\sigma_{1}, \sigma_{2}, \sigma_{3}\right)$, maximum shear stress $\tau_{\max }$ and maximum Von Mises stress $\sigma_{\text {von }}$ shown in Table 2 \&Table 3 respectively against contact ratio change for the contact area. The stresses generated on spur gear teeth change with the changing the contact ratio of gearing, where as the maximum generated stresses observed in low the contact ratio. When the contact ratio changed from (1.9) to (2.0), the decrease of stresses was more than the decrease of stresses when the contact ratio changed between any two other successive case. The value of contact ratio 1.6 and 1.7, 
Maximum von Mises stresses are higher than the yield strength of material. So, Failure of gear teeth is expected for low contact ratio.

\section{ACKNOWLEDGMENTS}

The author wishes to express the deepest thanks and gratitude to her supervisor Dr. Than Than Htike, Professor, Mechanical Engineering Department of Yangon Technological University The author special thanks go to Dr. Khin Thu Zar, Demonster, Mechanical Engineering Department of Technological University (Thanlyin), for her invaluable advice and effective suggestion throughout the study. The author would like to express her thanks to her member Daw Chaw Wint Yee Zaw, Lecture, Mechanical Engineering Department of Technological University (Thanlyin), for her valuable comments and indispensable guidance during this study. Finally, her special thanks to all who helped her towards the successful completion of this study.

\section{REFERENCES}

[1] M.V. Vamis, S.B., A.Sriram, "Spur Gear Tooth Stress Analysis and Stress Reduction", B-Tech Project Report, 2013.

[2] S.C, M., "Tooth Load Sharing and Contact Stress Analysis of High Contact Ratio Spur Gears in Mesh", National Convention of Mechanical Engineers, Roukela, 2002.

[3] A.H, E., "Tooth Load Sharing in High Contact Ratio Spur Gears", Journal of Mechanisms, Transmissions and Automation in Design, 1985. 107(1): p. 11-16.

[4] Harihapan, M., "Spur Gear Tooth Stress Analysis and Stress Reducing using Stress Reduction Geometrical Feacture". B-Tech, Thapar Institute of Engineering and Technology, 2006

[5] R, S.I., "Static and Dynamic Analysis of High Contact Ratio Spur Gear Drive". 2013.

[6] R.L, N., "Design of Machinery", Mc.Graw-Hill Companies Inc, U.S.A, New York, 2001.

[7] Maitra, G.M., "Handbook of Gear Design". Second Edition, 2001. Chapter-(2).

[8] G/marian, M., "Effect of Change of Contact Ratio on Contact Fatigue Stress of Spur Gear", Addis Ababa University, School of Graduate Studies, 2013.

[9] Lateno, E., "Effect of Change of Spur Gear Tooth Parameters on Bending and Contact Stresses", Addis Ababa University, 2014.

[10] M.J Puttock, E.G.T., "Elastic Compression of Sphere and Cylinders at Point and Line Contact". National Standard Laboratory Technical Paper, 1969. No.25. 